\title{
Generation After Next Propulsor Research: Robust Design for Embedded Engine Systems
}

\author{
David J. Arend ${ }^{1}$ \\ NASA Glenn Research Center, Cleveland, $\mathrm{OH} 44135$ \\ Gregory Tillman ${ }^{2}$ \\ United Technologies Research Center, East Hartford, CT 06108 \\ and \\ Walter F. O'Brien ${ }^{3}$ \\ Virginia Polytechnic and State University, Blacksburg, VA 24061
}

The National Aeronautics and Space Administration, United Technologies Research Center and Virginia Polytechnic and State University have contracted to pursue multidisciplinary research into boundary layer ingesting (BLI) propulsors for generation after next environmentally responsible subsonic fixed wing aircraft. This Robust Design for Embedded Engine Systems project first conducted a high-level vehicle system study based on a large commercial transport class hybrid wing body aircraft, which determined that a 3 to 5 percent reduction in fuel burn could be achieved over a 7,500 $\mathrm{nm}$ mission. Both pylonmounted baseline and BLI propulsion systems were based on a low-pressure-ratio fan (1.35) in an ultra-high-bypass ratio engine (16), consistent with the next generation of advanced commercial turbofans. An optimized, coupled BLI inlet and fan system was subsequently designed to achieve performance targets identified in the system study. The resulting system possesses an inlet with total pressure losses less than $0.5 \%$, and a fan stage with an efficiency debit of less than $1.5 \%$ relative to the pylon-mounted, clean-inflow baseline. The subject research project has identified tools and methodologies necessary for the design of nextgeneration, highly-airframe-integrated propulsion systems. These tools will be validated in future large-scale testing of the BLI inlet / fan system in NASA's $8 \mathrm{ft} \times 6 \mathrm{ft}$ transonic wind tunnel. In addition, fan unsteady response to screen-generated total pressure distortion is being characterized experimentally in a JT15D engine test rig. These data will document engine sensitivities to distortion magnitude and spatial distribution, providing early insight into key physical processes that will control BLI propulsor design.

\section{Nomenclature}

$\begin{array}{ll}0 & =\text { free stream } \\ \Delta U & =\text { velocity difference } \\ \eta_{p} & =\text { propulsive efficiency } \\ A E D C & =\text { Arnold Engineering Development Complex } \\ A I P & =\text { aerodynamic interface plane } \\ B L I & =\text { boundary layer ingesting } \\ B P F & =\text { blade passing frequency } \\ B W B & =\text { blended wing body } \\ C A E P & =\text { Committee on Aviation Environmental Protection } \\ C F D & =\text { computational fluid dynamics }\end{array}$

\footnotetext{
${ }^{1}$ Aerospace Engineer, AIAA Associate Fellow

${ }^{2}$ Principal Research Engineer, AIAA Associate Fellow

${ }^{3}$ J. Bernard Jones Professor of Mechanical Engineering, AIAA Associate Fellow
} 


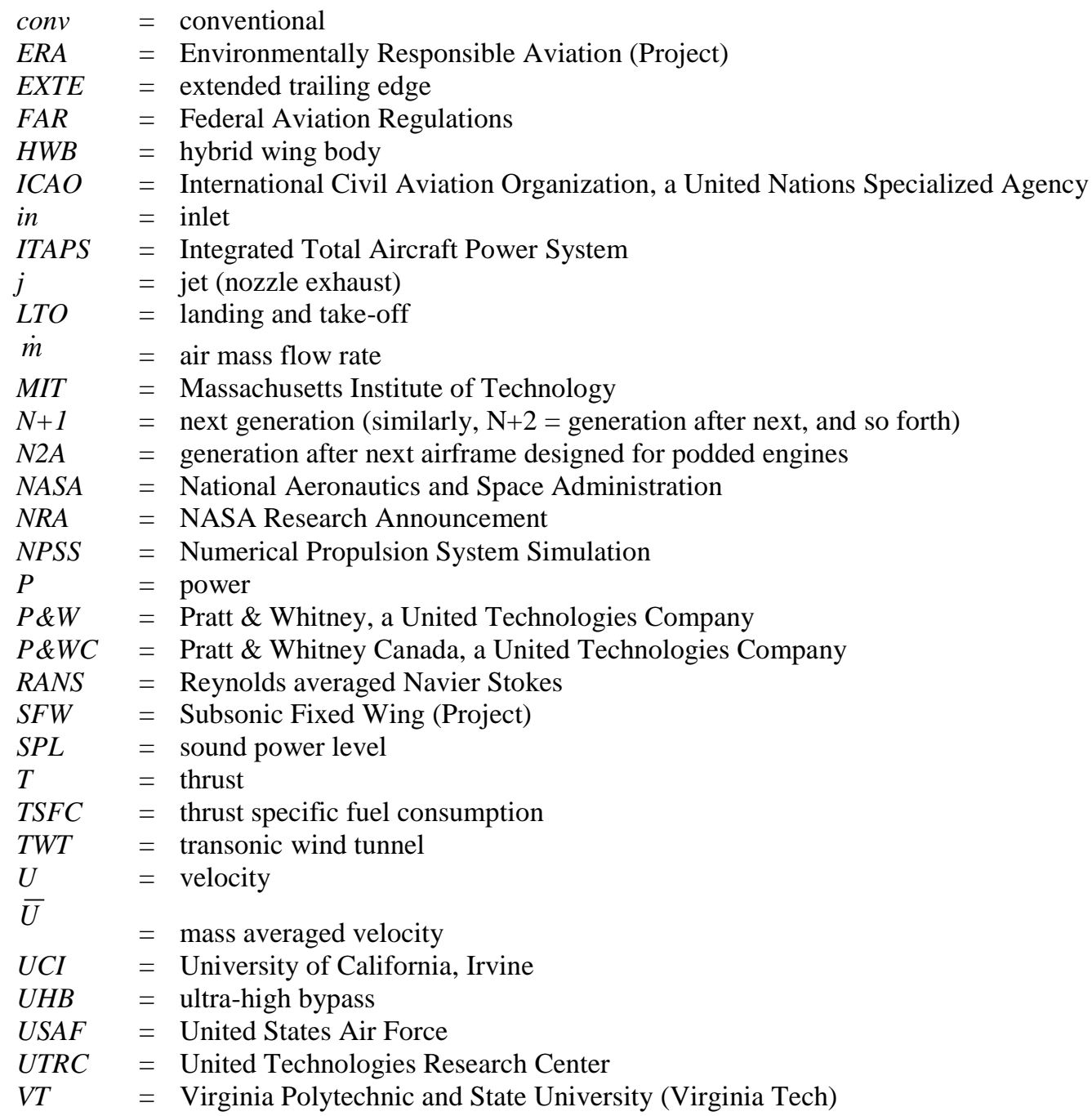

\section{Introduction}

$\mathbf{I}_{\mathrm{n}}^{\mathrm{N}}$ $\mathrm{N}$ order to address growing concerns over the increasing global environmental impact of aviation and the resulting need for improved aircraft technologies, the National Aeronautics and Space Administration (NASA) initiated fundamental aeronautics research through its Subsonic Fixed Wing (SFW) and later Environmentally Responsible Aviation (ERA) projects. Focused primarily on applications beginning with generation after next $(\mathrm{N}+2)$ aircraft, NASA, industry and university researchers are pioneering new technologies which have the potential to significantly reduce utilization of the world's finite petroleum resources, harmful atmospheric emissions and objectionable community noise levels. In order to stimulate and focus the national effort on solving these problems, NASA in 2006 established and continues to advance challenging aircraft system level metrics and goals by which to stimulate research progress. As shown in Figure 1, four technology benefit metrics have been defined. The first of these "corners of the trade space" metrics is limiting cumulative aircraft noise level at take-off, sideline and approach for landing operating conditions to below Federal Aviation Regulation (FAR) 36, Stage 4 specifications. The second and third metrics govern reductions in emissions of nitrogen oxides from Landing and Take-Off (LTO) to high altitude cruise operating conditions as set forth by the International Civil Aviation Organization's (ICAO's) Committee on Aviation Environmental Protection (CAEP). The fourth and final metric requires reductions in aircraft fuel (or as may be more applicable for certain aircraft types, energy) consumption and thereby ultimately aims to further reduce carbon dioxide emissions levels below the benchmark 2005 standard. Goal values which are to be met for each of these metrics are also provided for next $(\mathrm{N}+1)$ and succeeding generations of aircraft technology. 


\begin{tabular}{|c|c|c|c|}
\hline \multirow{2}{*}{$\begin{array}{l}\text { TECHNOLOGY } \\
\text { BENEFITS* }\end{array}$} & \multicolumn{3}{|c|}{$\begin{array}{l}\text { TECHNOLOGY GENERATIONS } \\
\text { (Technology Readiness Level = 4-6) }\end{array}$} \\
\hline & $\mathrm{N}+1$ (2015) & $\mathrm{N}+2(2020 * *)$ & $\mathrm{N}+3(2025)$ \\
\hline $\begin{array}{c}\text { Noise } \\
\text { (cum margin rel. to Stage 4) }\end{array}$ & $-32 \mathrm{~dB}$ & $-42 d B$ & $-71 d B$ \\
\hline $\begin{array}{l}\text { LTO } \mathrm{NO}_{\mathrm{x}} \text { Emissions } \\
\text { (rel. to CAEP 6) }\end{array}$ & $-60 \%$ & $-75 \%$ & $-80 \%$ \\
\hline $\begin{array}{c}\text { Cruise } \mathrm{NO}_{\mathrm{x}} \text { Emissions } \\
\text { (rel. to } 2005 \text { best in class) }\end{array}$ & $-55 \%$ & $-70 \%$ & $-80 \%$ \\
\hline $\begin{array}{l}\text { Aircraft Fuel/Energy Consumption } \\
\text { (rel. to } 2005 \text { best in class) }\end{array}$ & $-33 \%$ & $-50 \%$ & $-60 \%$ \\
\hline
\end{tabular}

* Projected benefits once technologies are matured and implemented by industry. Benefits vary by vehicle size and mission. $\mathrm{N}+1$ and $\mathrm{N}+3$ values are referenced to a $737-800$ with CFM56-7B engines. N+2 values are referenced to a 777-200 with GE90 engines.

** ERA's time-phased approach includes advancing "long-pole" technologies to TRL 6 by 2015.

$\mp \mathrm{CO}_{2}$ emission benefits dependent on life-cycle $\mathrm{CO}_{2 \mathrm{e}}$ per $\mathrm{MJ}$ for fuel and/or energy source used.

\section{Figure 1. NASA Environmentally Responsible Subsonic Transport System Level Metrics}

As is clear from Figure 1, NASA has set high goals as it strives to achieve large improvements for the public good. Such improvements cannot be obtained through incremental evolution of existing technologies alone. Major strides - new aircraft concepts and enabling innovations - are required. Such is the research being conducted by the Robust Design for Embedded Engine Systems project described here. Initiated through the award of an N+2 NASA Research Announcement ${ }^{1}$ (NRA) contract to United Technologies Research Center (UTRC) and Virginia Polytechnic and State University (VT) in alignment with in-house NASA research, the purpose of the Robust Design project is to contribute significantly toward meeting NASA's generation after next goals. In particular, Robust Design is focused on meeting the fourth goal, reducing aircraft fuel consumption by $50 \%$. However, by doing so, it is expected that significant indirect benefits will be realized for reducing both aircraft $\mathrm{NO}_{\mathrm{x}}$ emissions and noise as well.

The Robust Design for Embedded Engine Systems project is working to accomplish these goals through research into its embedded, boundary layer ingesting (BLI) propulsor concept integrated into a Hybrid Wing Body (HWB) or alternatively named Blended Wing Body (BWB) aircraft configuration. An illustration of this aircraft concept is provided in Figure 2. As its name implies, HWB aircraft combine desirable attributes possessed by conventional "tube and wing" and less often employed "flying wing" configurations in a way that mitigates their individual shortcomings. Much like a "flying wing" configuration, the entire form of an HWB aircraft is employed to generate lift, resulting in first order improvements in life-to-drag ratio. However, its shape and the inclusion of vertical stabilizers reduce its susceptibility to stability and control challenges. Together with recent progress being made for manufacturing non-axisymmetric pressurized cabins, ${ }^{2-4}$ HWB aircraft are becoming increasingly attainable. HWB aircraft do offer multiple performance benefits which continue to be actively explored. The hybrid wing body architecture does have the potential to achieve significant performance improvements toward each of NASA's N+2 goals. Important among these improvements is the fact that it provides for more and better opportunities for integration of embedded BLI propulsors than conventional aircraft configurations. 


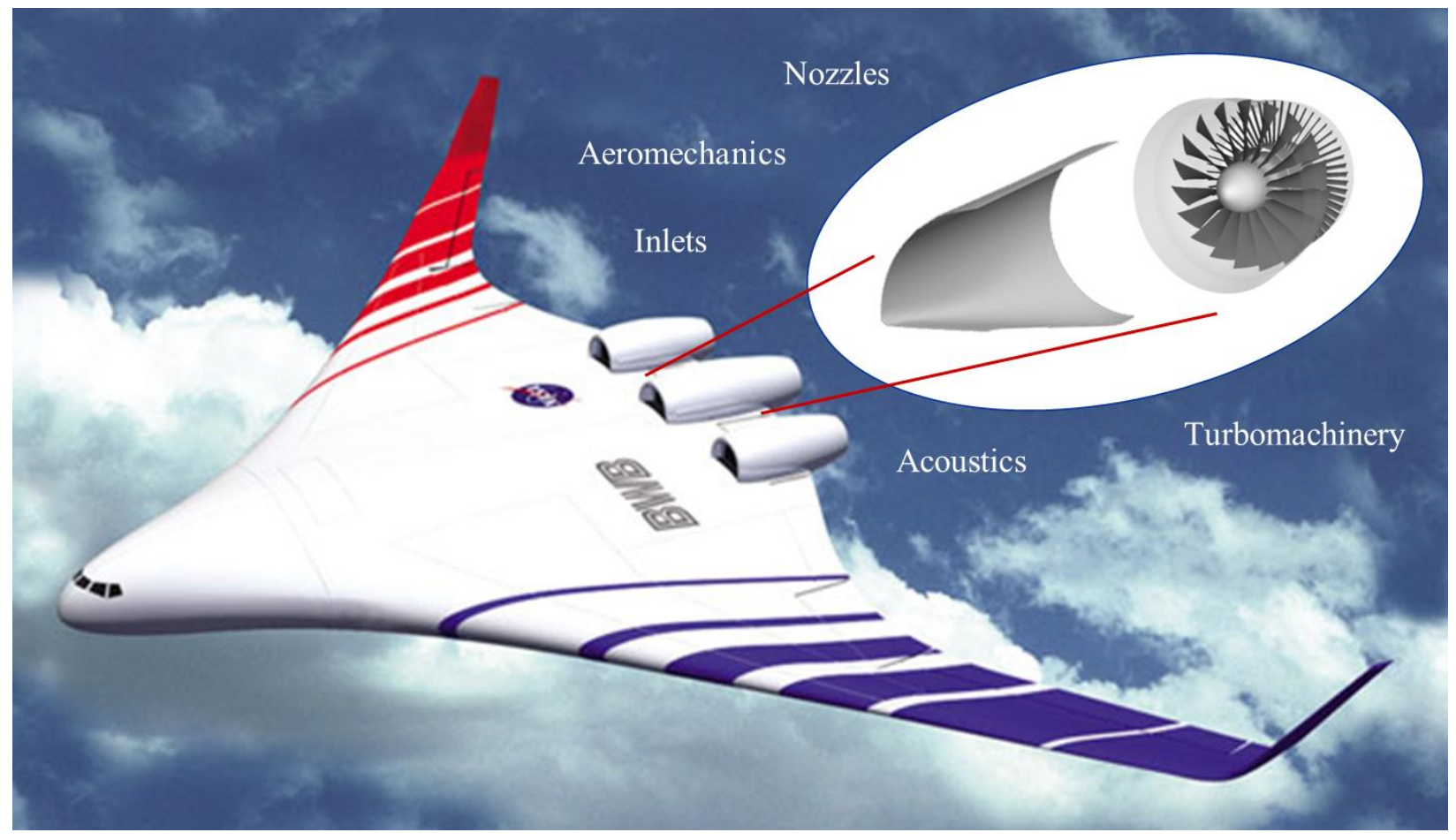

Figure 2. Embedded Boundary Layer Ingesting Propulsor Concept for Hybrid Wing Body Aircraft

Significant potential exists for the boundary layer ingesting propulsor concept. Indeed, these benefits were identified at least as early as 1947 by Smith ${ }^{5}$. Many investigations have been conducted since this time. ${ }^{6-11}$ Notably, Smith $^{12}$ and Drela ${ }^{13}$ provided methods for assessing and quantifying BLI benefits. A number of more recent aircraft systems studies ${ }^{14-19}$ have shown that embedded BLI propulsors are an important, enabling concept for meeting NASA's goals. These prospective benefits can be identified by conducting a one-dimensional comparative analysis as was done by Plas, et al. ${ }^{16-17}$ of a representative configuration with a conventionally installed (i.e. pod-mounted) turbofan engine. However, before doing so, it is important to note that the term propulsor is used here to refer to a designed-integrated, inlet-fan module of a turbofan engine. It does not include the engine's core gas generator. To facilitate this comparison, a graphical representation of each propulsion installation is provided in Figure 3 . The conventional installation on the left features an engine mounted some distance away from the aircraft fuselage such that it ingests air at velocity, $U_{\text {in,conv }}$, which is equivalent to the local free stream velocity, $U_{0}$, and exhausts flow through its fan nozzle at velocity, $U_{j, \text { conv }}$. In contrast, the embedded BLI propulsion installation on the right features an engine mounted directly to the vehicle body such that much of the airflow it ingests is composed of the aircraft generated boundary layer present there. As a result, it ingests air at the mass averaged velocity, $\bar{U}_{i n, B L I}$, of the combined boundary layer and local free stream air and exhausts flow from its fan nozzle at velocity, $U_{j, B L I}$.

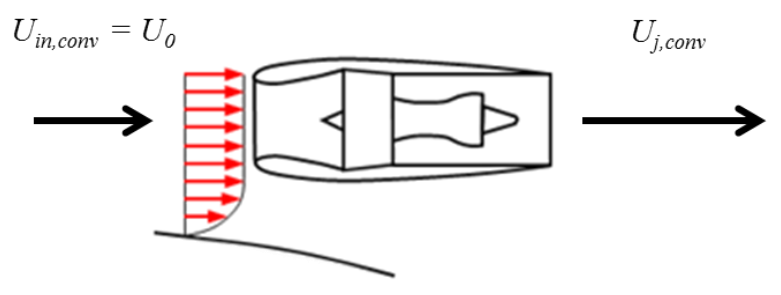

Conventional Propulsion

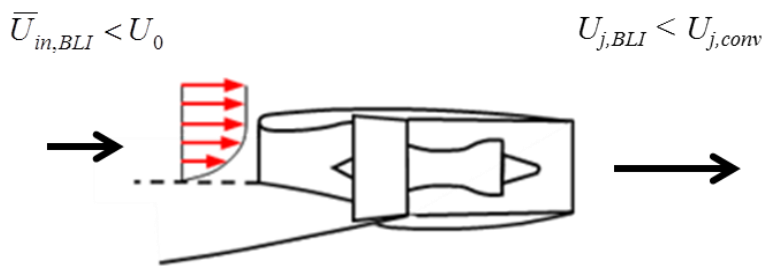

Boundary Layer Ingesting Propulsion

Figure 3. Comparison of Conventional and Boundary Layer Ingesting Propulsion Systems 
In both cases, energy ultimately derived from the combustion of fuel is added to the fan stream through work done on the airflow by turbomachinery. This action provides thrust as the resulting flow is accelerated through the fan nozzle. Neglecting the comparatively lower thrust and drag contributions due to the pressure distribution about the propulsor arrangement, the resulting familiar equations for thrust, $T$, and propulsive power, $P$, generated by airflow, $\dot{m}$, entering at velocity, $U_{i n}$, and exiting at velocity, $U_{j}$, are provided as Eqs. 1 and 2.

$$
\begin{aligned}
& T=\dot{m}\left(U_{j}-U_{i n}\right) \\
& P=\frac{\dot{m}}{2}\left(U_{j}^{2}-U_{i n}^{2}\right)
\end{aligned}
$$

Solving Eq. 1 for air mass flow rate and substituting into Eq. 2, provides the following equation between thrust and propulsive power where the velocity differential is defined as, $\Delta U=\left(U_{j}-U_{i n}\right)$.

$$
P=T\left(\frac{U_{i n}+U_{j}}{2}\right)=T\left(U_{i n}+\frac{\Delta U}{2}\right)
$$

Assuming constant aircraft drag (thrust required for maintaining steady level flight), it follows from Eq. 1 that the velocity differential, $\Delta U$, for a propulsor operating with constant air mass flow rate must also be constant. Yet under the same operating conditions, Eq. 3 provides that if the velocity of the ingested air is reduced, then the propulsive power required to produce this same thrust is itself reduced. This is precisely the case for BLI propulsors. The average velocity of the combined boundary layer and local free stream air being ingested is meaningfully lower than for the conventionally mounted propulsor. Returning to Eq. 1, the requirement for the BLI propulsor to maintain constant thrust while operating at constant mass flow rate and reduced (average) inflow velocity requires that the nozzle exhaust velocity also be reduced. Altogether, this result can be better understood in terms of propulsive efficiency, which is defined for the conventional and BLI systems respectively as Eqs. 4 and 5.

$$
\begin{gathered}
\eta_{p, \text { conv }}=\frac{2}{\left(1+\frac{U_{j, c o n v}}{U_{0}}\right)} \\
\eta_{p, B L I}=\frac{2 U_{0}}{\bar{U}_{i n, B L I}+U_{j, B L I}}
\end{gathered}
$$

Solving Eq. 4 for the free stream velocity both concepts share, substituting the result into Eq. 5 and simplifying provides the following equation for the propulsive efficiency of a BLI propulsor in terms of the efficiency of the convention propulsor and relative velocities.

$$
\eta_{p, B L I}=\left(\frac{U_{0}+U_{j, c o n v}}{\bar{U}_{i n, B L I}+U_{j, B L I}}\right) \eta_{p, c o n v}
$$

As was determined above, the vehicle boundary layer flow has already been diffused whereas the local free stream airflow has not $\bar{U}_{i n, B L I}<U_{0}$ which permits a reduced velocity jet exhaust flow $U_{j, B L I}<U_{j, c o n v}$ to provide the same thrust. So, if sufficient boundary layer can be efficiently ingested and designs and technologies can be researched and developed to either accommodate or sufficiently mitigate the negative impacts of ingesting boundary layer flow on the propulsor's component efficiencies, then by Eq. 6 the propulsive efficiency of the BLI configuration is expected to be meaningfully higher than that of its conventional counterpart. Less propulsive power is required to produce the required thrust.

BLI propulsors are anticipated to have further benefits which can be appreciated more directly. In particular, attaching the aircraft's engines directly to the fuselage eliminates the need for and weight of support pylons. 
Additionally, some of the required nacelle structure may be able to be combined with existing vehicle structure. Depending on how much the aircraft body's structure may need to be strengthened locally to support the engine's weight and thrust loads, further weight reductions may be possible. Aerodynamic drag is also anticipated to be lower due to the elimination of wetted surface area associated with removal of the support pylons and nacelle structure that has been combined with the aircraft's body. Interference drag between pylons, nacelles and the airframe may be reduced. Finally, an aircraft with reduced jet velocity BLI propulsors could realize meaningful reductions in noise.

In pursuit of these prospectively identified benefits for meeting NASA's system level metrics, the goal of the Robust Design for Embedded Engine Systems project is to determine the feasibility, performance and operability potential of and advance technologies for the realization of embedded boundary layer ingesting propulsors for hybrid wing body aircraft. Although the focus of the present effort is on HWB aircraft, it is anticipated that the technologies being researched will be applicable to other aircraft types as well. In order to achieve this goal, the Robust Design project has set for itself three main objectives. They are (1) to build upon knowledge gained from prior industry, NASA and academic research efforts (2) to conduct a high level propulsion system study to ensure that the design space to be explored is relevant and (3) to design, fabricate and test an integrated BLI inlet-fan propulsor that simultaneously achieves less than $2 \%$ reductions in both fan efficiency and stability margin relative to a pod-mounted advanced UHB baseline propulsion system with a conventional inlet and an associated UHB fan stage designed to incorporate current (2010) technology.

To be sure, multiple technical challenges exist which must be overcome in order to accomplish these objectives. The first of these is mitigation and/or accommodation of airflow distortion presented to the fan as a result of ingesting large amounts of aircraft boundary layer flow. The second challenge is the development of computational tools which are capable of aerodynamically designing and analyzing the combined inlet and fan stage. Third, supporting component and subcomponent technologies need to be identified and developed to provide the design features required to meet the established research objectives. These include means of ameliorating distortion in the inlet and/or accommodating it in the fan stage. Fourth, aeromechanics modeling tools and techniques need to be developed to assess and analyze the impacts of BLI distortion on fan stage structures. Finally, acoustic assessments are required to establish a baseline propulsor noise level for and to aid in the mitigation of any objectionable noise characteristics which may be developed by the embedded BLI design. Clearly surmounting these complex multidisciplinary challenges is a significant undertaking.

\section{Approach}

The approach taken by the Robust Design for Embedded Engine Systems project to surmount the complex challenges outlined above has been through a complementary, multi-disciplinary effort both within and across the previously identified research teams. To date, core research elements of the project have been conducted by UTRC and Virginia Tech. NASA has also defined its objectives, assessed their feasibility and conducted multi-disciplinary research. Complementary technical and programmatic foundations for the project were subsequently laid. Building on that foundation, work initially focused on conducting systems studies to gain insight into the problem, set the technical direction of the project and ensure the continuing relevance of its work. Computational design, analysis and experimentation of necessarily increasing fidelity and sophistication were planned and continue to be implemented to accomplish the project's research objectives. The Robust Design project's research is ultimately set to culminate in the experimental test of a large scale BLI propulsor in NASA's $8 \mathrm{ft}$ x $6 \mathrm{ft}$ Transonic Wind Tunnel (TWT).

The project used as a point of reference a propulsor made up of a conventional axisymmetric subsonic inlet and a technology-upgraded (i.e. to 2010) baseline G4 ultra-high bypass ratio fan stage (Bypass Ratio $=16$, Fan Pressure Ratio $=1.35$ ) previously designed by Pratt $\&$ Whitney for NASA. Progress made into BLI inlet and distortiontolerant fan technologies and designs was measured against this standard. Initially, high level performance, operability, aeromechanics and acoustics assessments were used for risk reduction and to make technical course corrections. Requirements provided by the inlet and fan design drove the nozzle development including the generation of a new variable area subsonic nozzle design tool. The research team also tapped engineering design and facilities engineering support earlier in the design and analysis process than usual to ensure its success. Multidisciplinary research support is provided in the areas of inlets, turbomachinery, aeromechanics, acoustics and nozzles. Additionally, NASA Langley is tasked with the design of the experiment's external nacelle. The United States Air Force (USAF) Arnold Engineering Development Complex (AEDC) is providing facility integration computational fluid dynamic (CFD) support. 
As identified above, a systems study was conducted to ensure the relevance of the research so defined and provide technological insight which NASA can use to chart its future, generations into the future fundamental aeronautics research and technologies investments. In so doing, the Robust Design team endeavored to identify a relevant area of the propulsion and airframe integration design space most likely to afford success. The subject systems study was based on a common reference (i.e. the Boeing N2A-EXTE Hybrid Wing Body) aircraft as reported by Tillman ${ }^{20}$ and described in detail by Hardin. ${ }^{21}$ Owing to its high level treatment of the subject, this system study should be regarded as providing quality initial insight and guidance for researching BLI propulsors for HWB aircraft applications. A full accounting of the details of this study is provided in a following section of this paper.

Guided by the results of the systems study, a multi-disciplinary holistic approach has been consistently utilized throughout the conduct of the remainder of this research. Following the system study, detailed inlet and fan designs were carried out using CFD tools. Inlet designs were first explored across a wide region of parameter space using a toolset developed under an earlier phase of this project. ${ }^{22}$ Subsequent coupled inlet / fan design was initially conducted in a loosely-coupled mode, whereby isolated inlet flow field results were used as an inflow boundary condition for the design of the fan. This step was used in the design process because it enabled a relatively large number of design iterations to be accomplished before more detailed fully-coupled calculations were implemented. Fan design studies and impact analyses were conducted using a series of inlets designed to successively improve the distortion pattern delivered to the fan. The inlet designs also targeted reduced inlet total pressure losses, which can provide large detrimental impacts to the overall engine cycle performance.

Following the loosely-coupled design step, fully-coupled analyses were carried out. These full fan stage, unsteady CFD computations included the upstream airframe flow field and the inlet, fan, and fan exit guide vanes. More specific analysis of the fan stage was also included in this portion of the study, with fully-coupled analyses of the fan and fan exit guide vanes using selected inlet inflow boundary conditions. The inlet and fan designs were thus conducted in a manner of successively increased levels of computational analysis, and coupling of the various aerodynamic elements. This coupled approach was found to be critical in capturing the dominant physical processes occurring in the inlet, fan, and fan exit guide vanes for the subject BLI propulsor design. The strong aerodynamic coupling between these components was expected due to the highly-airframe-integrated nature of the overall BLI propulsion system, and is described by Florea, et. al in a companion paper. ${ }^{23}$

Propulsion system noise will be an important aspect of any BLI design. Acoustic assessments were therefore made at key waypoints in the inlet and fan design process. Ingestion of distorted airflow typically increases the noise generated by a jet engine. A key advantage of ultra-high-bypass engine cycles is their inherent low-noise characteristics provided by the reduced jet velocities and lower fan tip speeds. When integrated into the aft region of a blended wing body or hybrid wing body aircraft, an additional benefit of forward noise shielding can also be expected. This is anticipated to mitigate increases in noise due to distortion ingestion. Aft shielding of jet noise may be less important with the reduced jet velocities inherent in ultra-high-bypass turbofans. However, inlets may be challenged for adequate surface area for the installation of acoustic treatment, so forward-radiated inlet tone noise was evaluated analytically to obtain a preliminary understanding of this noise mechanism and associated sensitivities.

In planning the project, it became clear that a better grasp of coupled BLI inlet and turbofan engine performance and operability in the presence of BLI distortion was needed. Going beyond prior work such as that of $\operatorname{Reid}^{24}$, fan rotor response to unique BLI distortion patterns, intensities and flow component properties needed to be better understood so that inlets and fans could subsequently be designed to reduce and eliminate adverse responses for such installations. Indeed, this additional knowledge was needed to support and enhance the design and test of the BLI propulsor experiment to be conducted by the Robust Design team. To meet this need, Virginia Tech planned experimental investigations to examine the flow produced in and by a BLI inlet and to measure its JT15D engine fan's response to such distortions. ${ }^{25-27}$ Owing to its part-span shroud which limited aeromechanical blade deflections, the JT15D engine was viewed as being well suited for this pioneering propulsion research. Initiated early in the Robust Design project before its inlet or fan were designed, this effort leveraged the high quality,

computational and experimental database which resulted from prior research conducted by NASA Langley. ${ }^{28-35}$ That is, its focus was on evaluating the challenging uncontrolled distortion of Inlet A. 


\section{System Study}

As stated earlier, the research being done on the BLI propulsor originated in the work previously done by NASA Langley. ${ }^{28-35}$ The goal of that effort ${ }^{36}$ was to research flow control technologies for difficult highly offset BLI inlet distortion problems. The MIT/Cambridge University Silent Aircraft Initiative team placed the emphasis of its vehicle design on noise reduction and so by definition did not provide a completely balanced design between the competing requirements of noise, fuel burn and structural weight ${ }^{37}$. Given the amount of research results reported to date, the Robust Design team initiated its effort by assessing the state of the whole of this technology and drew much benefit from that work. On that basis the project team identified promising BLI propulsor technologies, planned and executed its research. This work was begun by conducting a propulsion system study.

With the multitude of possible integration architectures, it is critical to design BLI propulsion in a manner consistent with achieving net vehicle-level fuel burn benefits. In order to identify such BLI propulsion concepts, a trade-factor-based system study was defined and executed prior to conducting more detailed coupled inlet / fan design to ensure that subsequent concepts would meet the desired vehicle-level performance targets. This study utilized boundary layer profiles and the external flow field associated with the Boeing N2A-EXTE hybrid wing body aircraft, and is described in detail by Hardin et. al. ${ }^{21}$ The HWB reference vehicle was designed for a 7,500 nautical mile mission and is within the large commercial transport class. The design cruise Mach number was 0.8 at an altitude of 35,000 feet. The reference propulsion system for the current study was an Ultra-High-Bypass (UHB) turbofan, with a cycle chosen to have a bypass ratio of 16 and a fan pressure ratio of 1.35 . This type of engine is consistent with the $\mathrm{N}+2$ time frame, and would employ a suite of advanced technologies in the engine core, bypass stream, and nacelle. The system study attempted to capture the vehicle-level impacts associated with each of the following elements: boundary layer ingestion; changes in propulsion system drag; changes in inlet / nacelle weight; changes in inlet pressure losses and fan efficiency due to operation in distorted flow; and flow control subsystem weight and power extractions. These elements were estimated using low-order, empirical-based models, combined with higher-fidelity modeling of the coupled inlet / fan aerodynamic performance and the engine thermodynamic cycle.

Propulsion system performance changes due to BLI operation were accounted for by using the Numerical Propulsion System Simulation (NPSS) engine cycle model, modified for use in a BLI environment by Hardin ${ }^{21}$. A flow chart depicting the resulting modified NPSS calculations is provided in Figure 4. Use of the same airframe and engine cycle for both podded and BLI configurations was done to ensure a more precise evaluation of BLI benefits exclusive of any other airframe or engine features. With boundary layer ingestion, the degree of coupling between the airframe and the engines is significantly enhanced relative to legacy propulsion / airframe installations, requiring new approaches for analyzing and designing BLI propulsion systems.

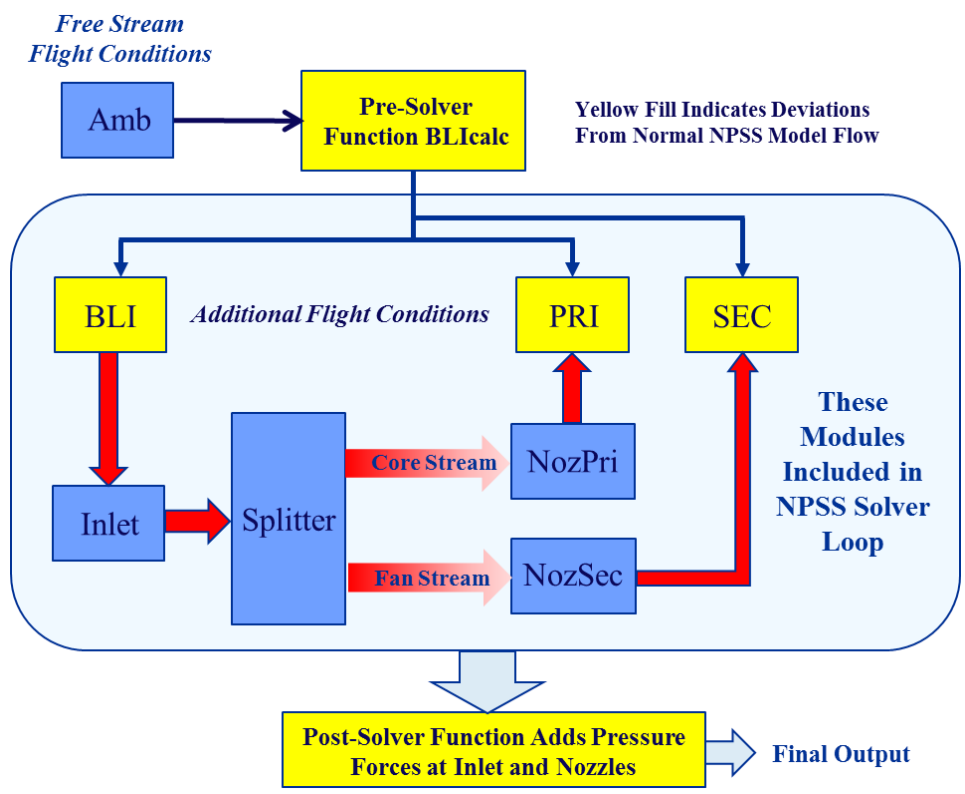

Figure 4. Pratt \&Whitney NPSS Cycle Model Modified to Include Boundary Layer Ingestion 
The BLI cycle studies were run with a nominal fan efficiency, inlet pressure recovery, and other cycle inputs. To account for performance penalties associated with reduced fan efficiency, increased inlet pressure losses, and flow control bleed or power extractions, the baseline (podded) NPSS cycle model was executed over a range of each parameter to determine the sensitivity of the engine TSFC, the basic measure of cycle performance, to those elements. The reason for this approach was to eliminate the need to rerun the NPSS model as better estimates of the inlet and fan performance were obtained throughout the course of on-going, more detailed aerodynamic design of these components.

As described earlier, low-order models were used to estimate the effects of nacelle weight and drag. The weight model was empirically-based, and captured the effect of fan diameter (and resulting nacelle diameter) changes on nacelle weight. Inlet weight impacts were also estimated for designs that added additional inlet length beyond that associated with the nacelle (for example, increased inlet aspect ratios that pushed the inlet forward on the airframe). Inlet drag was also an empirically-based model that scaled nacelle drag based upon the wetted area change relative to the pylon-mounted baseline nacelle. Inlet pressure losses were initially estimated using results from initial CFD analyses conducted during an earlier phase of the project, ${ }^{22}$ but were then supplemented with more detailed CFDbased inlet design results in current phase. Fan performance impacts were also estimated using the higher-fidelity, loosely-coupled fan design results as described above. Finally, where flow control systems were employed to improve inlet flow quality and pressure losses, subsystem weight and bleed / power extractions were estimated from previous studies and these debits included in the overall system performance assessment.

Aircraft-level trade factors for the Boeing N2A-EXTE vehicle were derived from the corresponding trade factors for a synthesized large commercial transport vehicle defined by UTRC in recent Integrated Total Aircraft Power Systems (ITAPS) studies ${ }^{38}$ of several vehicles of similar size and range. The trade factors corresponded to a vehicle that was scaled based upon required fuel load. Fuel burn was the primary metric that was used in the aircraft-level system study trades, and so associated vehicle-level trade factors for propulsion system TSFC, drag, and weight were defined. To estimate the mission fuel burn for a specified engine/airframe architecture, a starting estimate of TSFC was obtained from tabulated results of the NPSS analysis of the percentage of BLI flow. Then, estimates of additional inlet losses, fan efficiency losses, engine bleed and power extractions and in cases of highly embedded configurations, low pressure compressor losses were combined with the corresponding sensitivities to provide TSFC impacts associated with these effects. The TSFC-to-fuel-burn trade factor was then used to calculate the fuel burn impact of each of the effects. Incremental weight and drag estimates and the associated aircraft trade factors were then used to compute these fuel burn impacts, and the net fuel burn for the architecture in question was determined by summing all of the individual contributions. Results of the study showed that BLI designs can provide on the order of a 3-5\% fuel burn reduction relative to an advanced, pylon-mounted, UHB reference propulsion system. ${ }^{20-21}$

The optimal configuration has five BLI propulsors arrayed near the trailing edge of the HWB vehicle.

A key outcome of the system study was the identification of compact, low-offset inlets that are needed to provide low total pressure loss and reduced nacelle drag. These attributes were found to be of key importance in being able to realize net system-level benefits with BLI propulsion. In addition, a low-loss, distortion-tolerant fan was also identified as a key BLI technology. Both of these components are highly coupled with each other and with the airframe in BLI installations, and thus need to be designed using tools that properly account for the coupling effects.

\section{Computational Analyses}

As described earlier, coupled, CFD-based aerodynamic analyses were carried out to design the coupled inlet / fan element of the BLI propulsion system. The inlet design process is described in detail by Florea, et al. ${ }^{23}$ As described in this work, the inlet is governed by several design parameters including aspect ratio, duct offset, lengthto-diameter ratio, and wall shape. The desire to address multiple design objectives in the presence of such broad parameter space drove the need to utilize an existing optimization-based, parametric inlet design tool assembled during an earlier phase of the project. Initial parametric design was done for the inlet alone. Following this initial exploration of design space, the process coupled the inlet to the fan, and coupled inlet / fan design was carried out for selected designs. The CFD flow solver utilized within the inlet flow simulation and optimization was CFL3D ${ }^{39}$, a robust, mature code originally developed by NASA and currently in use in industry and academia. For the higher fidelity coupled inlet / fan analysis Pratt \& Whitney's aerodynamic flow solver ${ }^{40}$ was used. 


\section{A. Inlet Design and Analysis}

The inlet design process of the Robust Design project originated in the research into Inlet A completed by NASA Langley ${ }^{28-29,31-34}$. Inlet A was highly offset, had a length-to-diameter ratio of 3.0 and an excess inlet total pressure loss (i.e. total pressure loss occurring within the inlet itself, not including that already incurred by the ingested boundary layer) of $1.8 \%$. This process utilized an optimizer that implemented controlled changes to the parameters governing the inlet design. The optimizer drove the design to achieve the prescribed objectives which was a balance between performance and distortion. This process can also be executed in a parametric design mode, whereby hundreds or thousands of cases describing the parameter space of interest can be automatically executed. Post-processing can be used to screen / filter the results, and attractive regions of design space can be evaluated subsequently in greater detail. Following the parametric design, a more detailed viscous design can then be carried out, either with the inlet alone or the coupled inlet / fan in either a steady mixing-plane mode or as an unsteady, higher-fidelity simulation. Upon selection of the most attractive geometries for further analysis, a loose coupling back to the system study analysis was carried out in order to ensure that resulting geometries were consistent with achieving system-level fuel burn benefits. To accomplish this, the inlet total pressure loss, fan efficiency impact, and ingested boundary layer fraction were input to the system study tool and a refined fuel burn estimate generated. For specific cases, the geometry features can be modified or refined and cases set-up again for another pass through the parametric design tool. In this fashion, inlet design progression can be continuously linked to the high-value inlet design space identified in the system study, and preservation of the system-level benefits can be assured as the design progresses.

For several geometries selected from the parametric study, high-fidelity local shaping was carried out on the inlet walls using the surface and grid morphing tool. Tens of degrees of freedom were used to define inlet wall shaping and the cost function was a weighted combination of pressure harmonic content and total pressure loss. The inlet design was thus initiated by the selection of key high-value design space defined by the system study, and progressed in a layered fashion with first isolated global inlet parametric design, followed by more detailed and higher-fidelity local optimization-based design.

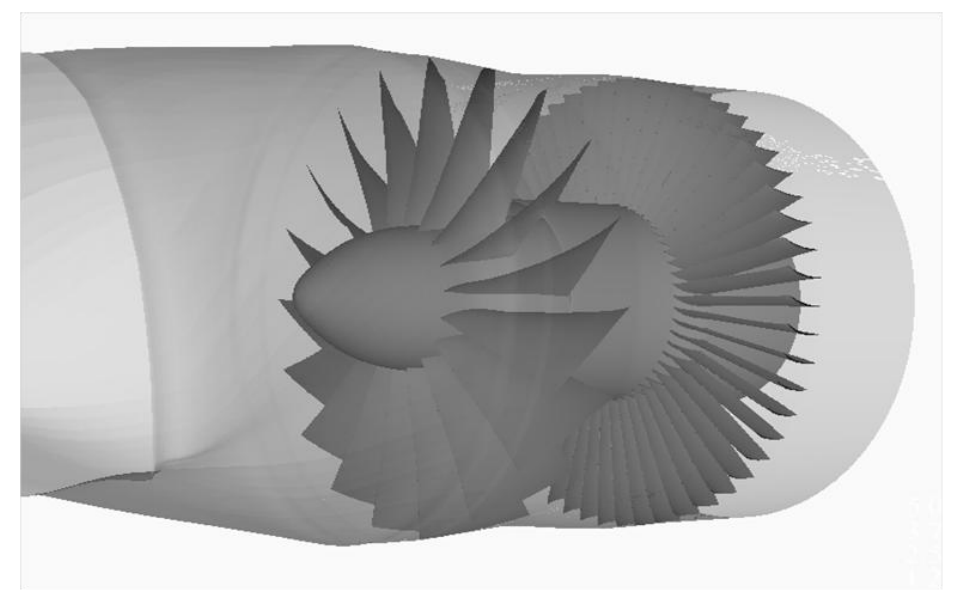

Figure 5. Boundary Layer Ingesting Inlet-Fan Propulsor Concept

\section{B. Fan Design and Analysis}

At various stages of this design process, both loosely-coupled and fully-coupled inlet / fan design analyses were carried out to evaluate impacts on fan performance. As the flow develops through the inlet and into the fan, the flow at the fan face is characterized both by total pressure distortion resulting from momentum losses in the incoming boundary layer and swirl distortion. Swirl distortion can be created by the internal duct shape, offset, or other effects while total pressure distortion is largely manifested in the form of momentum losses in the boundary layer development on the airframe. Total pressure losses can be further amplified as the flow enters the inlet and progresses from the highlight to the fan face. Ultimately, both total pressure and swirl distortion lead to large spatial variations of blade-relative incidence. ${ }^{23,41}$ Together, the excursions in blade relative incidence and the top-to-bottom imbalance of mass flow / total pressure over the fan have a first-order impact on the fan performance, operability, and aeromechanic response. ${ }^{23}$ 
As described by Sharma, ${ }^{41}$ and subsequently by Florea, et al., ${ }^{23}$ this impact was first characterized by evaluating the baseline fan in a loosely-coupled manner with NASA's Inlet A without its flow control. Inlet A represents a highly-offset, relatively long inlet design consistent with a deeply embedded propulsion system. At its design cruise flight conditions, the analysis showed that a $6 \%$ reduction in fan efficiency resulted from the impact of the uncontrolled Inlet A flow on the fan. This adverse impact was enough to offset most of the system-level fuel burn benefit associated with BLI. ${ }^{21}$ Subsequent inlet design and coupled inlet / fan design were able to reduce this impact on fan efficiency to less than $1.5 \%$, preserving the BLI benefits and reducing other adverse impacts on the fan such as aeromechanic response. Clearly, the coupled inlet / fan design approach has been shown to be critical in the development of BLI propulsion system components.

\section{Aeromechanic Analysis}

An analysis tool used extensively in the rotorcraft community was employed to predict the fan blade structural modes and aerodynamic damping characteristics in order to perform preliminary characterizations of fan aeromechanic response. This tool, Rotorcraft Comprehensive Analysis System (RCAS), was also able to predict blade deflections. An initial study was conducted which focused upon the prediction of deflections, blade stresses, and structural vibratory modes. The commercially-available SOLIDWORKS finite-element-based software package was used to provide steady and unsteady blade stresses to supplement the RCAS modeling.

The RCAS tool consists of a high order nonlinear beam finite element model, including the pertinent nonlinear geometric terms associated with gyroscopic and centrifugal effects. The finite element assembly is based on deformed coordinates that allows for large beam deflections. Since the methodology was originally developed for helicopter applications, the wake inflow model is necessarily different from what might be expected for a fan, so the way in which RCAS was used for the current application involved a step to tie the wake inflow model of RCAS back to air loads predicted on the blade from CFD. The current RCAS air-load model treats each 3-D rotor blade as a series of 2-D airfoil sections and calculates the section air loads based on local section aerodynamic parameters. Section lift, drag, and pitching moment are computed based on blade element momentum theory and are applied as loads to the 1-D beam analysis. For the current fan application, the blade section aerodynamic properties can be developed either from CFD or other 2-D airfoil theory. Using this approach, the RCAS wake inflow model was used both to simulate clean-inflow operation, and the effect of inflow distortion on the fan. This modeling approach was able to be executed rapidly, with a throughput of tens of cases on a daily basis for screening of designs. Once the fan design reached a given level of maturity, more detailed aeromechanics modeling was employed to verify performance. These modeling results are the subject of a companion paper, where high-fidelity aeromechanics analyses are presented for a BLI fan operating at cruise. ${ }^{42}$

As described by Bakhle, ${ }^{42}$ boundary layer ingesting propulsion systems have the potential to significantly reduce fuel burn but the system must overcome challenges related to aeromechanics. One challenge is forced response dynamic stress due to the operation of the fan/propulsor in a non-uniform or distorted flow field resulting from the boundary layer ingestion. High dynamic stresses can be a concern since these can lead to fatigue failure of blades through repeated cycles of vibration. The unique consideration for BLI propulsion systems is that the distortion pattern is persistent. In contrast, a conventional aircraft's podded engines encounter distorted inflow only at zero or low forward speed due to flow separation on the nacelle lip caused by cross-wind and high angles of attack. Another important consideration is that the BLI inlet introduces a flow distortion that can contain multiple harmonics or sources of excitation. A third aeromechanics challenge is flutter stability of the fan operating in a distorted inflow. Although flutter and forced response are often considered separately using a linear formulation, unexpected changes in flutter stability characteristics may occur due to nonlinear interactions between a large distortion and blade vibrations.

On the subject project, the TURBO-AE aeroelastic analysis code ${ }^{43-44}$ is used to study the aeromechanical characteristics of the BLI fan in both clean and distorted inflows. Briefly, TURBO-AE is an implicit finite-volume time-domain solver of Reynolds-averaged Navier Stokes (RANS) equations that uses structured multi-block grids to model flow through one or more blade rows. An inlet distortion boundary condition is used at the upstream boundary to prescribe the flow entering the fan domain since the inlet duct is not modeled in this part of the work. For fan aeromechanics analysis with blade vibrations, dynamic grid deformation is used to prescribe harmonic blade vibrations and the energy method is used to evaluate aerodynamic damping and flutter stability.

Since the design of the BLI fan is in progress, the detailed analyses summarized by Bakhle ${ }^{42}$ are those which were performed on an intermediate aerodynamic design iteration. A structural model is created to obtain the vibration mode shapes and frequencies for aeromechanics analysis. A Campbell diagram was constructed to understand the potential interactions between the harmonic excitations from the distorted inflow and the natural frequencies of the fan blades at various rotational speeds. A modal forced response analysis is performed that 
includes the effects of each harmonic excitation from the inlet distortion on various vibration modes. This analysis was used to calculate the dynamic stresses at design rotational speed. Further analysis is required to examine the forced response dynamic stresses at other rotational speeds where the engine order excitation frequency coincides with a blade natural frequency (on-resonance conditions), which can result in significantly higher dynamic stresses. Fan flutter stability is evaluated using the TURBO-AE aeroelastic analysis code to calculate aerodynamic damping. Analysis was done for a clean inflow, followed by analysis for distorted inflow. Both peak efficiency and near-stall conditions were considered at design rotational speed. Primary bending and torsion modes were evaluated separately over a range of nodal diameter patterns. The aerodynamic damping near stall is seen to drop to very low values. However, none of the results showed negative aerodynamic damping that would indicate flutter. Further analysis is required at off-design conditions where flutter is more frequently encountered.

\section{Acoustic Assessments}

As described earlier, it was desired to perform predictions of the acoustic power in the fan near-field in order to quantify inlet noise level changes associated with the fan. This analysis was carried out using internally-developed acoustic prediction tools that use fan blade and near-field CFD pressure predictions as the primary input. The analysis was restricted to steady loading noise at the Blade Passage Frequency (BPF). The aerodynamic design point case was analyzed as a representative condition, and takes advantage of the symmetry in the problem which allowed for the analysis of a single fan passage.

The G4 fan was used to perform these noise studies. Changes in the fan near-field Sound Power Level (SPL) were estimated for several fan geometries spanning a range of rotor sweep and lean. Overall, the inlet tone noise sound power level changes were seen to be relatively small amongst the various fan blade architectures studied. The largest change was approximately a 3-4 dB inlet SPL reduction, associated with an aft-swept blade geometry. As described earlier, it is likely that for advanced UHB propulsion system cycles integrated onto blended wing body or hybrid wing body airframes, inlet noise will not be a major driver in the overall system design. Moreover, differences in predicted inlet tone noise levels for the various fan blade architectures are seen to be relatively small for clean inflow operating conditions and will be unlikely to provide a significant differentiation in distortiontolerant fan design concepts provided that additional forward radiated noise due to distorted inflow is adequately shielded by the HWB airframe.

\section{Experimental Research}

Experiments are planned to provide critical insight into the problem of fan rotor response to BLI distortion, check computational predictions obtained for the inlet, fan and aeromechanics and to provide data which cannot be obtained from CFD analyses (e.g. flow structures involving turbulence). Carefully targeted efforts which build cumulatively toward a large-scale multi-disciplinary wind tunnel test of an integrated BLI inlet-fan propulsor have been planned to answer key questions. These modular, multi-use experiments and special test support equipment are being developed to maximize the present and future return on project investments. The technical foundation has been set and associated plans made to assure that valid tests are conducted (e.g. Reynolds number) relative to past paradigms and the engines identified for the prospective full-scale aircraft in accordance with the results of the systems study.

\section{A. Foundational Distortion Experiment}

As previously mentioned, it is necessary to mitigate and/or accommodate highly non-uniform inlet flow provided to commercial turbofan engines in order to realize the benefits of BLI propulsion. In order to gain important insight into fan response to such distortion patterns, a dedicated distortion response test rig was designed and built. A computer generated rendering of this rig including a cutaway view showing its internal features are provided in Figure 6. These features include a flight inlet, adjustable modular sections of constant diameter tunnel, a sealed precision rotating screen assembly and a 60-probe fixed geometry steady state Aerodynamic Interface Plane (AIP) rake array attached to a Pratt \& Whitney Canada (P\&WC) JT15D engine. Each of the tunnel sections is standardized and so permit both the rotating screen assembly and AIP rake array to be installed at different axial stations along the variable length tunnel. This permits both decoupled (i.e. from the engine) screen calibrations and coupled distortion response experimental tests to be conveniently performed using the same rig. The fan stage of the JT15D engine was itself modified for this experiment to include a radially plunging high response probe. It is positioned axially between the fan rotor and outlet guide vanes. Photographs showing both the AIP rake array and high response probe are provided in Figure 7. 
Flow measurements have been made to verify and calibrate the rig's intended operation. It is important to note that the Virginia Tech rig is located within a test cell fitted with doors which open both in front of and behind the experiment. Due to the configuration of the test cell walls, sufficient flow is induced through the "flow through" test cell around the engine which prevents the formation or ingestion of ground vortices or unintended distortion shed from equipment located on the external surfaces of the rig aft of the inlet lip. This rig has been used to calibrate the needed distortion screens and to ascertain the JT15D fan rotor's response to simulated uncontrolled (i.e. no inlet flow control present) distortion issuing from Inlet A. Data was acquired at conditions matching those at which CFD calculations ${ }^{25}$ have been performed and experimental wind tunnel data ${ }^{28,31}$ have been acquired by NASA Langley. The precision screen rotating mechanism permitted measurement of the fan's response to both inlet distortion intensity and angular extents with its radially plunging inter-stage high response probe. This probe was mounted to a computerized traverse that accurately positioned the probe to acquire measurements across the fan duct annulus. A control system has been devised and implemented to automate test sequences (i.e. screen rotation and probe position) once the engine has arrived on condition.
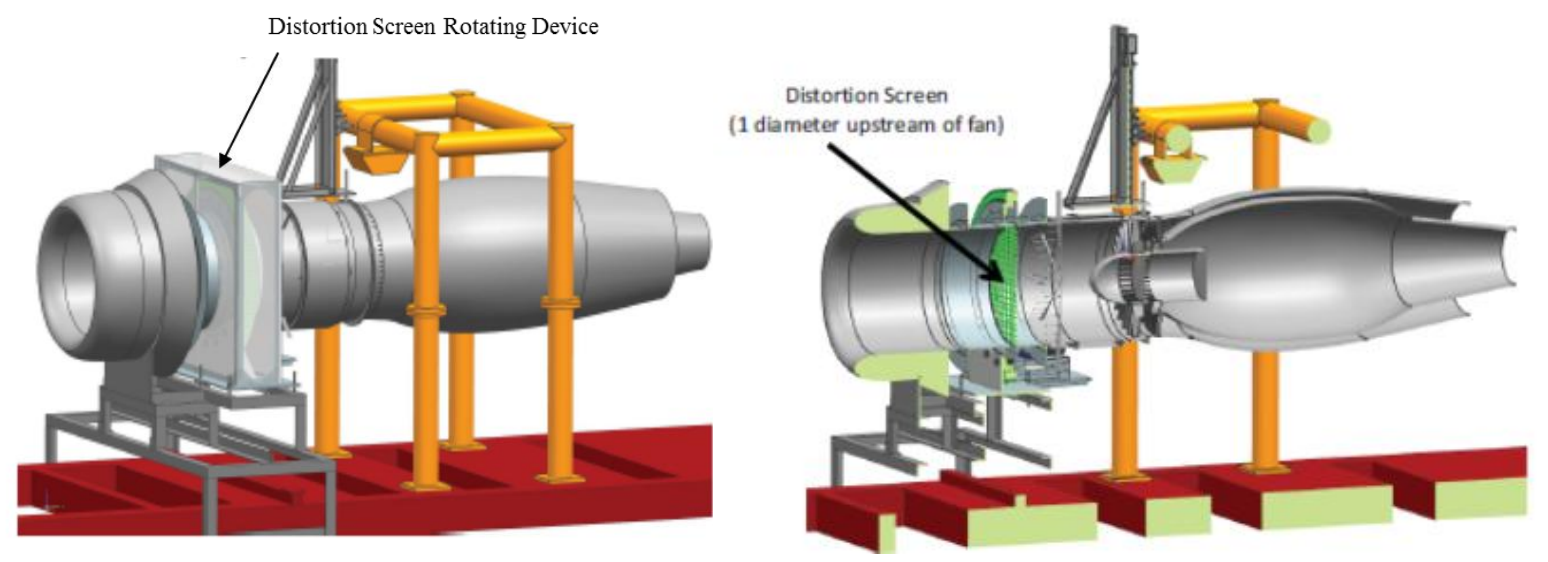

Figure 6. Virginia Tech Distortion Research Test Rig (Distorted Inflow Testing Configuration)

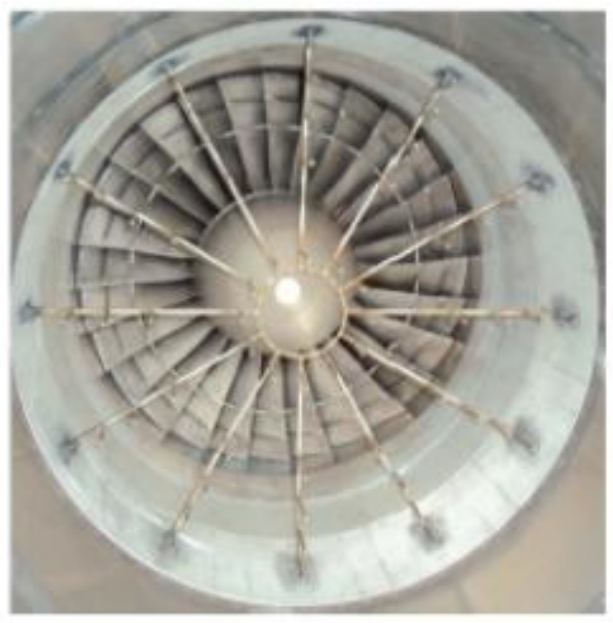

AIP Rake

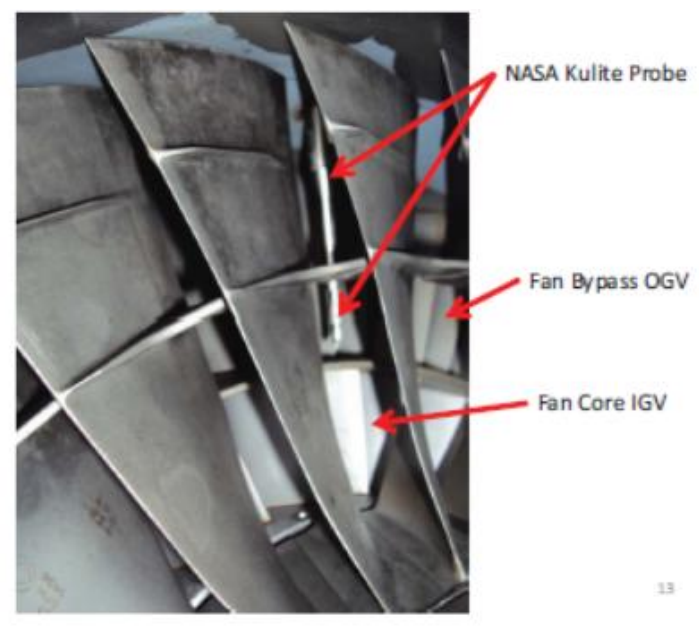

High Response Flow Probe

Figure 7. Virginia Tech Distortion Research Test Rig (Instrumentation) 


\section{B. Multi-Disciplinary Wind Tunnel Experiment}

A large-scale 8'x6' Transonic Wind Tunnel (TWT) test of a multi-use, BLI distortion tolerant propulsor experiment has been defined which initially focusses on aircraft cruise operating conditions. It consists of a single boundary layer ingesting inlet coupled with a 22 " diameter distortion-tolerant fan stage mounted into raised wind tunnel floor special test equipment designed to simulate the upper aft surface of a hybrid wing body aircraft. As shown in Figure 9, this experiment is designed to ingest the naturally developed wind tunnel floor boundary layer regulated by a dedicated boundary layer bleed system. The experiment is to be powered by NASA's Ultra-High Bypass (UHB) fan drive rig. The experiment itself is being designed to include a rotating combined steady state and high response AIP rake array. Also included is a rotating fan exit rake array featuring sufficient steady state stagnation pressure and temperature sensors to accurately measure fan stage efficiency. Also included is a sufficiently fast-acting, mass flow calibrated, variable area fan nozzle that is being designed to be able to "safe" the experiment in the event of any encountered fan stage structural instabilities. Aerodynamic performance, operability and health monitoring measurements will be made of the calibrated wind tunnel flow field, inlet and fan stage as well as aeromechanic measurements of the fan rotor. Aerodynamic shaping is also being employed within the wind tunnel in an effort to not only simulate the correct boundary layer thickness, but if possible to also provide the boundary layer shape factor computed for the local aircraft flow environment. Testing is to be done in phases focused mostly on the aircraft design cruise conditions. This experiment will also be capable of off-design tests including lower speed flight conditions and reduced fan power settings. A blockage analysis has been completed to ensure that the planned tests can be conducted successfully.

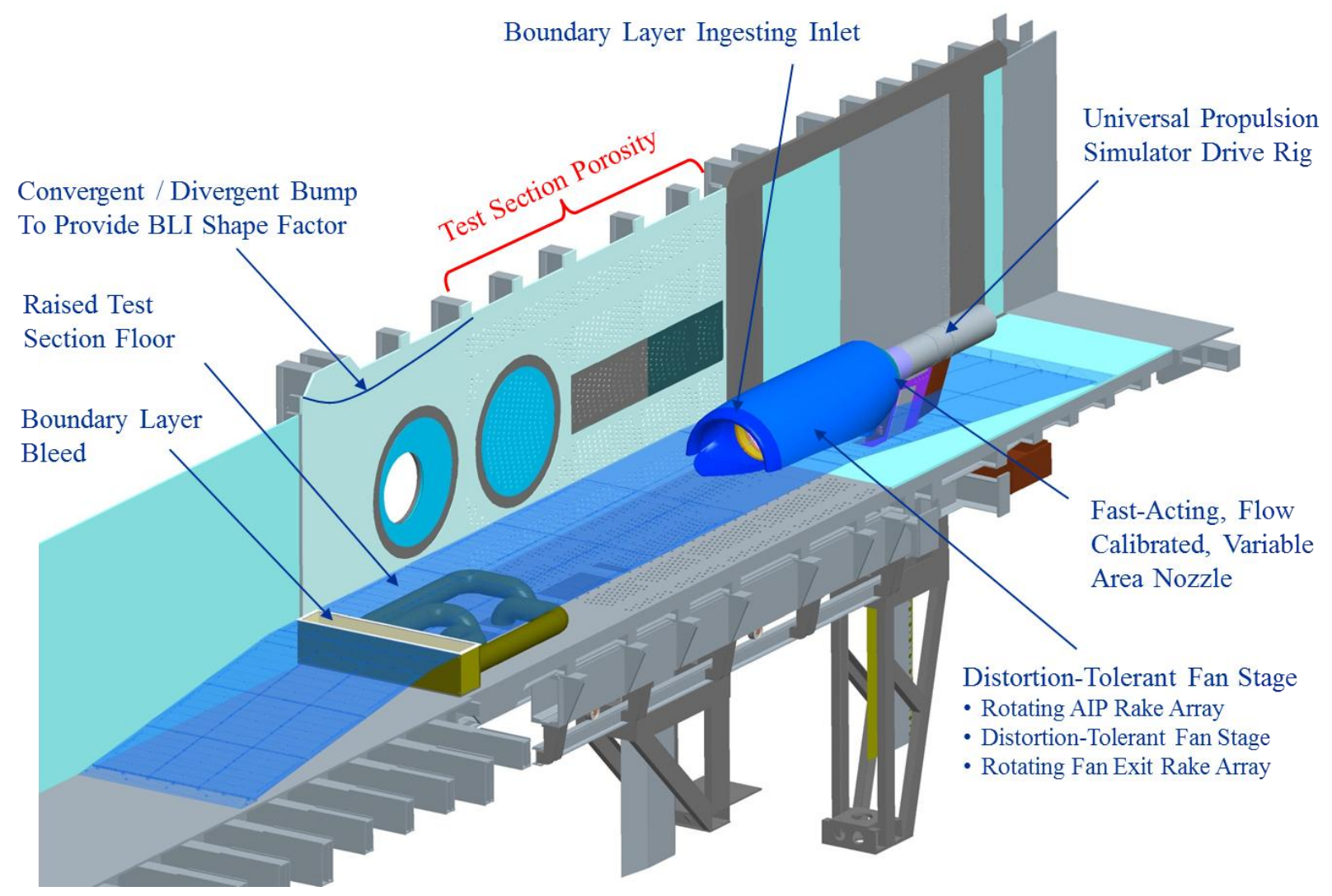

Figure 9. Robust Design Boundary Layer Ingesting Propulsor Experiment Layout 


\section{Results}

Detailed results from the Robust Design project reporting the aircraft system study, inlet design, fan aeromechanics analysis, and fan response distortion testing are contained in companion papers by Hardin, et al. ${ }^{21}$, Florea et al. ${ }^{23}$, Bakhle et al., ${ }^{42}$ and Ferrar and O'Brien, ${ }^{45}$ respectively. The system study employed a combination of low-order and higher fidelity models of the various inputs, and utilized engine sensitivities and aircraft trade factors to estimate block fuel burn reduction for a long-range commercial transport mission. Results of the study showed that a 3-5\% BLI fuel burn benefit can be achieved for $\mathrm{N}+2$ aircraft relative to a baseline high-performance, pylonmounted, UHB propulsion system. High-performance, distortion-tolerant turbomachinery, and low-loss, low-drag inlet systems, were identified as key enabling technologies. Detailed inlet parametric design was carried out to define an inlet with significantly reduced length, total pressure loss, and distortion harmonic energy content relative to a highly-offset, embedded reference BLI inlet (NASA Inlet A). Inlet excess total pressure losses (i.e. losses within the inlet itself, not including the total pressure deficit of the ingested boundary layer) were reduced to less than $0.5 \%$, and the impact on fan efficiency was reduced from $6 \%$ for the reference Inlet A case to less than $1.5 \%$ with the current inlet design.

A first evaluation of BLI fan aeromechanics response was carried out using high-fidelity modeling of the fan operating at cruise. A three-dimensional, time-accurate, Reynolds-averaged Navier Stokes computational fluid dynamics code was used to characterize the fan in response to both clean and distorted inflows. Results of this study show an intermediate design iteration of the fan to be flutter-free at the design conditions analyzed with both clean and distorted in-flows. Although cruise operation is traditionally not a limiting case for aeromechanics response, for BLI operation the cruise point is an appropriate condition at which to conduct an initial characterization of the challenges in this new design environment. As this area of research progresses, key off-design operating conditions such as takeoff rotation, aircraft maximum lift, and cross-wind will also be included in design analyses.

Experiments to characterize fan response to total pressure distortion patterns of varying magnitude and spatial extent have been conducted using a JT15D engine test rig. High-response instrumentation was used to measure the fan unsteady response as it moves from locally clean inflow through the simulated BLI distortion. These data have documented engine sensitivities to distortion magnitude and spatial distribution, and thereby provide insight into key physical processes that control BLI propulsor design. Again, for detailed treatment of system study, inlet design, fan aeromechanics modeling, and JT15D fan testing, the relevant companion papers may be consulted. ${ }^{21,23,42,45}$

\section{Summary}

A well founded and technically compelling research project - Robust Design for Embedded Engine Systems has been defined and implemented in order to determine the feasibility and potential of and advance technologies for embedded hybrid wing body propulsors. A propulsion system study has been completed based on a large commercial transport class hybrid wing body aircraft that has determined that five boundary layer ingesting, distortion tolerant, ultra-high bypass ratio (16), low fan pressure ratio (1.35) turbofan engines mounted along the upper aft surface of the body portion of the aircraft offer the best chance for achieving NASA's stated generation after next aircraft technology system level metrics. A technology upgraded baseline ultra-high bypass ratio turbofan engine has been defined from which the performance and operability of the BLI propulsors will be measured. Computational tools have been developed and a multi-variable optimized inlet has been designed and analyzed with an excess inlet total pressure loss of $0.50 \%$. Foundational distortion experiments utilizing distortion screens to simulate BLI flow distortion entering a P\&WC JT15D turbofan engine have been completed. Their results have contributed fundamental understanding of fan response to BLI distortion in support of the design of a distortiontolerant fan stage. The design of the distortion-tolerant fan stage with a resulting efficiency deficit of less than 1.5\% is nearly complete. Significant low and high-order accurate aeromechanics analyses have been completed using the G4 fan stage. Analyses of an interim distortion-tolerant fan stage have determined it to be flutter free. Multiobjective (cruise) wind tunnel tests are planned to evaluate the resultant propulsor configuration. This experiment is being designed to support multiple future investigations. The Robust Design project is well poised to make significant contributions to reducing the impact of aviation on the environment. 


\section{Acknowledgments}

The authors wish to thank Drs. Ruben Del Rosario, Richard Wahls, Nateri Madavan and Michael Hathaway of NASA's Subsonic Fixed Wing Project as well as Drs. Fayette Collier, Kenneth Suder and Dale Van Zante of NASA's Environmentally Responsible Aviation Project for their collective financial support, interest and encouragement. The authors would also like to sincerely thank Mr. Ronald Kawai of the Boeing Company for the expert input he provided both at the inception of the Robust Design project's systems study and in subsequent consultations. Many thanks go to Dr. Florence Hutcheson and Mr. Gregory Gatlin for their interest and willingness to share data across our two projects. D. J. Arend also wishes to thank Mr. Terrance Dubreus of the USAF AEDC and Mr. James Sirbaugh of Aerospace Testing Alliance for administering and providing computational fluid dynamic analysis support for the integration of the Robust Design for Embedded Engine Systems experiment.

\section{References}

${ }^{1}$ Amendment No. 4 to the NASA Research Announcement (NRA) Entitled "Research Opportunities in Aeronautics - 2006 (ROA-2006)," NNH06ZEA001N, Released May 23, 2006.

${ }^{2}$ Velicki, A., Thrash, P., and Jegley, D. "Airframe Development for the Hybrid Wing Body Aircraft," AIAA Paper 20090932, 47 ${ }^{\text {th }}$ AIAA Aerospace Sciences Meeting and Aerospace and Exhibit, Orlando, FL, January 5-8, 2009.

${ }^{3}$ Velicki, A., and Jegley, D. "PRSEUS Development for the Hybrid Wing Body Aircraft," AIAA Paper 2011-7025, AIAA Centennial of Naval Aviation Forum: 100 Years of Achievement and Progress, Virginia Beach, VA, September 21-22, 2011.

${ }^{4} \mathrm{Li}$, V., and Velicki, A., "Advanced PRSEUS Structural Concept Design and Optimization,” AIAA Paper 2008-5840, 12 AIAA/ISSMO Multidisciplinary Analysis and Optimization Conference, Victoria, B.C. Canada, September 10-12, 2008.

${ }^{5}$ Smith, A. M. O., and Roberts, H. E., "The Jet Airplane Utilizing Boundary Layer Air for Propulsion," IAS Journal of the Aeronautical Sciences, Vol. 14, No. 2, 1947, pp. 97-109.

${ }^{6}$ Liebeck, R. H., Page, M. A., Rawdon, B. K., "Blended-Wing-Body Subsonic Commercial Transport," AIAA Paper 19980438, $36^{\text {th }}$ AIAA Aerospace Sciences Meeting and Exhibit, Reno, NV, January 12-15, 1998.

${ }^{7}$ Anderson, B. H., and Gibbs, J., "Vortex-Generator Installation Studies on Steady State and Dynamic Distortion," Journal of Aircraft, Vol. 35, No. 4, pp. 513-520, 1998.

${ }^{8}$ Liebeck, R. H., "Design of the Blended-Wing-Body Subsonic Transport," AIAA Paper 2002-0002, 40 ${ }^{\text {th }}$ AIAA Aerospace Sciences Meeting and Exhibit, Reno, NV, January 14-17, 2002.

${ }^{9}$ Liebeck, R. H., "Blended Wing Body Design Challenges," AIAA Paper 2003-2659, AIAA/ICAS International Air and Space Symposium and Exhibition: The Next Hundred Years, Dayton, OH, July 14-17, 2003.

${ }^{10}$ Liebeck, R. H., "Design of the Blended Wing Body Subsonic Transport," AIAA Journal of Aircraft, Vol. 41, No. 1, January-February, 2004, pp. 10-25.

${ }^{11}$ Anderson, B. H., "A Study of the Blended Wing Body Outboard Inlet S-Duct with BLI Control," NASA Glenn Research Center, Unpublished Report.

${ }^{12}$ Smith, L., Jr., "Wake Ingestion Propulsion Benefit," AIAA Journal of Propulsion and Power, Vol. 9, No. 1, JanuaryFebruary, 1993, pp. 74-82.

${ }^{13}$ Drela, M., "Power balance in Aerodynamic Flows," AIAA Paper 2009-3762, $27^{\text {th }}$ AIAA Applied Aerodynamics Conference, 22-25 June 2009.

${ }^{14}$ Daggett, D. L., Kawai, R. T., and Friedman, D. M., "Blended Wing Body Systems Studies: Boundary Layer Ingestion Inlets with Active Flow Control," NASA/CR-2003-212670, December, 2003.

${ }^{15}$ Kawai, R. T., Friedman, D. M., and Serrano, L., "Blended Wing Body (BWB) Boundary Layer Ingestion (BLI) Inlet Configuration and System Studies," NASA/CR-2006-214534, December, 2006.

${ }^{16}$ Plas, A. P., "Performance of a Boundary Layer Ingesting Propulsion System," S.M. Thesis, Aeronautics and Astronautics Department, Massachusetts Institute of Technology, Cambridge, MA, 2006.

${ }^{17}$ Plas, A. P., Sargeant, M. A., Madani, V., Crichton, D., Greitzer, E. M., Hynes, T P., and Hall, C. A., "Performance of a Boundary Layer Ingesting (BLI) Propulsion System," AIAA Paper 2007-0450, 45 ${ }^{\text {th }}$ AIAA Aerospace Sciences Meeting and Exhibit, 8-11 January 2007.

${ }^{18}$ Kawai, R. T., "Quiet Cruise Efficient Short Take-Off and Landing Subsonic Transport System,” NASA/CR-2008-215141, April, 2008.

${ }^{19}$ Nickol, C. L., and McCullers, L. A., "Hybrid Wing Body Configuration System Studies," AIAA Paper 2009-0931, 47 AIAA Aerospace Sciences Meeting and Exhibit, Orlando, FL, January 5-8, 2009.

${ }^{20}$ Tillman, T. G., Hardin, L. W., Moffitt, B. A., Sharma, O. P., Lord, W. K., Berton, J., and Arend, D., "System-Level Benefits of Boundary Layer Ingesting Propulsion. Invited paper," 49th AIAA Aerospace Sciences Meeting, Orlando, FL, Jan. 47, 2011.

${ }^{21}$ Hardin, L. W., Tillman, G., Sharma, O. P., Berton, J., and Arend, D. J., "Aircraft System Study of Boundary Layer Ingesting Propulsion," AIAA Paper 2012-3993, 48th AIAA/ASME/SAE/ASEE Joint Propulsion Conference and Exhibit, Atlanta, GA, July 29 - August 1, 2012. 
${ }^{22}$ Florea, R. V., Reba, R., VanSlooten, P. R., Sharma, O. P., Stucky, M., O’Brien, W. F., and Arend, D. J., "Preliminary Design for Embedded Engine Systems," AIAA Paper 2009-1131, 47 ${ }^{\text {th }}$ AIAA Aerospace Sciences Meeting and Exhibit, Orlando, FL, January 5-8, 2009.

${ }^{23}$ Florea, R. V., Matalanis, C., Hardin, L. W., Stucky, M., and Shabbir, A., "Parametric Analysis and Design for Embedded Engine Inlets," AIAA Paper 2012-3994, 48th AIAA/ASME/SAE/ASEE Joint Propulsion Conference and Exhibit, Atlanta, GA, July 29 - August 1, 2012.

${ }^{24}$ Reid, C., "The Response of Axial Flow Compressors to Intake Flow Distortions," ASME Paper No. 69-GT-29, 1969.

${ }^{25}$ Ferrar, A. M., O'Brien, W. F., Ng, W. F., Florea, R. V., and Arend, D.J., "Active Control of Flow in Serpentine Inlets for Blended Wing-Body Aircraft," AIAA Paper 2009-4901, 45 ${ }^{\text {th }}$ AIAA/ASME/SAE/ASEE Joint Propulsion Conference and Exhibit, Denver, CO, August 2-5, 2009.

${ }^{26}$ Ferrar, A. M., Schneck, W. C., and O’Brien, W. F., "Flow in a Boundary Layer Ingesting Serpentine Inlets," AIAA Paper 2011-5568, 47 ${ }^{\text {th }}$ AIAA/ASME/SAE/ASEE Joint Propulsion Conference and Exhibit, San Diego, CA, July 31-August 3, 2011.

${ }^{27}$ Ferrar, A. M., and O'Brien, W. F., "Measurements of Fan Response to Boundary Layer Ingesting Inlet Distortion," NASA Fundamental Aeronautics Program Technical Conference Presentation, Cleveland, OH, March 14, 2012.

${ }^{28}$ Berrier, B. L., and Allan, B. G., "Experimental and Computational Evaluation of Flush-Mounted, S-Duct Inlets," AIAA Paper 2004-0764, 42 ${ }^{\text {nd }}$ AIAA Aerospace Sciences Meeting and Exhibit, Reno, NV, January 5-8, 2004.

${ }^{29}$ Allan, B. G., Owens, L. R., and Berrier, B. L., "Numerical Modeling of Active Flow Control in a Boundary Layer Ingesting Offset Inlet," AIAA Paper 2004-2318, $2^{\text {nd }}$ AIAA Flow Control Conference, Portland, OR, June 28 - July 1, 2004.

${ }^{30}$ Campell, R. L., Carter, M. B., Pendergraft Jr., O. C., Friedman, D. M., and Serrano, L., "Design and Testing of a Blended Wing Body with Boundary Layer Ingestion Nacelles at High Reynolds Number (Invited)," AIAA Paper 2005-0459, 43 ${ }^{\text {rd }}$ AIAA Aerospace Sciences Meeting and Exhibit, January 10-13, 2005.

${ }^{310}$ Berrier, B. L., Carter, M. B., and Allan, B. G., "High Reynolds Number Investigation of a Flush-Mounted, S-Duct Inlet with Large Amounts of Boundary Layer Ingestion," NASA/TP-2005-213766, September, 2005.

${ }^{32}$ Allan, B. G., and Owens, L. R., "Numerical Modeling of Flow Control in a Boundary-Layer-Ingesting Offset Inlet Diffuser at Transonic Mach Numbers," AIAA Paper 2006-0845, 44 ${ }^{\text {th }}$ AIAA Aerospace Sciences Meeting and Exhibit, Reno, NV, January 9-12, 2006.

${ }^{33}$ Allan, B. G., Owens, L. R., and Lin, J. C., "Optimal Design of Passive Flow Control for a Boundary-Layer-Ingesting Offset Inlet Using Design-of-Experiments," AIAA Paper 2006-1049, 44 ${ }^{\text {th }}$ AIAA Aerospace Sciences Meeting and Exhibit, Reno, NV, January 9-12, 2006.

${ }^{34}$ Owens, L. R., Allan, B. G., and Gorton, S. A., "Boundary-Layer-Ingesting Inlet Flow Control,” AIAA Paper 2006-0839, $46^{\text {th }}$ AIAA Aerospace Sciences Meeting and Exhibit, Reno, NV, 9-12 January, 2006.

${ }^{35}$ Carter, M. B., Campbell, R. L., Pendergraft Jr., O. C., Friedman, D. M., and Serrano, L., "Designing and Testing a Blended Wing Body with Boundary-Layer Ingestion Nacelles," AIAA Journal of Aircraft, Vol. 43, No. 5, September-October 2006, pp. 1479-1489.

${ }^{36}$ Allan, B. G., Personal Communication. Ultra-Efficient Engine Technology: Highly Integrated Inlet Element BLI Inlet Research, 2008

${ }^{37}$ Nickol, C. L., "Silent Aircraft Initiative Concept Risk Assessment,” NASA/TM-2008-215112, February, 2008.

${ }^{38}$ Ochs, S., Personal Communication. UTRC Large Commercial Transport ITAPS Study, October 2007.

${ }^{39}$ CFL3D Version 6.6 Home Page. http://cfl3d.larc.nasa.gov/.

${ }^{40}$ Davis, R. L., Ni, R. H., and Carter, J. E., "Cascade Viscous Flow Analysis Using the Navier-Stokes Equations," AIAA Journal of Propulsion and Power, Vol. 3, No. 5, pp. 406-414, 1987.

${ }^{41}$ Sharma, O. P., "Design of High-Performance Boundary Layer Ingesting Propulsion Systems," IGTI Panel Lecture, June 2011.

${ }^{42}$ Bakhle, M. A., Reddy, T. S. R., Herrick, G. P., Shabbir, A. and Florea, R. V., "Aeromechanics Analysis of a Boundary Layer Ingesting Fan," AIAA 48th AIAA/ASME/SAE/ASEE Joint Propulsion Conference \& Exhibit, July 29 - August 1, 2012.

${ }^{43}$ Chen, J.-P., and Whitfield, D. L., "Navier-Stokes Calculations for the Unsteady Flowfield of Turbomachinery," AIAA Paper 1990-0676, January 1990.

${ }^{44}$ Chen, J.-P. and Briley, W. R., “A Parallel Flow Solver for Unsteady Multiple Blade Row Turbomachinery Simulations," ASME Paper GT2001-0348, June 2001.

${ }^{45}$ Ferrar, A. M., and O’Brien, W. F., "Fan Response to Total Pressure Distortions Produced by Boundary Layer Ingesting Serpentine Inlets," AIAA Paper 2012-3996, 48th AIAA/ASME/SAE/ASEE Joint Propulsion Conference and Exhibit, Atlanta, GA, July 29 - August 1, 2012.

${ }^{46}$ Bakhle, M. A., Reddy, T. S. R., and Stefko, G. L., "Comparisons of Flutter Analyses for an Experimental Fan,” NASA/TM2010-216221, Apr. 2010.

${ }^{47}$ Lieblein, S., and Roudebus, W. H., "Low-Speed Wake Characteristics of Two-Dimensional Cascade and Isolated Airfoil Sections," NASA TN 3771, October, 1956.

${ }^{48}$ Bangert, L. H., Krivec, D. K., and Segall, R. N., "Effects of Nacelle Configuration/Position on Performance of Subsonic Transport," NASA CR-3743, November, 1983.

${ }^{49}$ Cousins, W. T., O’Brien, W. F., et. Al., "The Dynamics of Stall and Surge Behavior in Axial-Centrifugal Compressors," Ph.D. Dissertation, Mechanical Engineering Department, Virginia Polytechnic and State University, Blacksburg, VA, 1997. 